\title{
The TOR signaling cascade regulates gene expression in response to nutrients
}

\author{
Maria E. Cardenas, ${ }^{1,7}$ N. Shane Cutler, ${ }^{1}$ Michael C. Lorenz, ${ }^{1}$ Charles J. Di Como, ${ }^{6}$ \\ and Joseph Heitman ${ }^{1-5}$ \\ ${ }^{1}$ Departments of Genetics, ${ }^{2}$ Pharmacology and Cancer Biology, ${ }^{3}$ Microbiology, and ${ }^{4}$ Medicine, ${ }^{5}$ the Howard Hughes Medical \\ Institute, Duke University Medical Center, Durham, North Carolina 27710 USA; ${ }^{6}$ Department of Biological Sciences, \\ Sherman Fairchild Center, Columbia University, New York, New York 10027 USA
}

Rapamycin inhibits the TOR kinases, which regulate cell proliferation and mRNA translation and are conserved from yeast to man. The TOR kinases also regulate responses to nutrients, including sporulation, autophagy, mating, and ribosome biogenesis. We have analyzed gene expression in yeast cells exposed to rapamycin using arrays representing the whole yeast genome. TOR inhibition by rapamycin induces expression of nitrogen source utilization genes controlled by the Ure 2 repressor and the transcriptional regulator Gln3, and globally represses ribosomal protein expression. gln3 mutations were found to confer rapamycin resistance, whereas ure 2 mutations confer rapamycin hypersensitivity, even in cells expressing dominant rapamycin-resistant TOR mutants. We find that Ure2 is a phosphoprotein in vivo that is rapidly dephosphorylated in response to rapamycin or nitrogen limitation. In summary, our results reveal that the TOR cascade plays a prominent role in regulating transcription in response to nutrients in addition to its known roles in regulating translation, ribosome biogenesis, and amino acid permease stability.

[Key Words: Rapamycin; TOR kinase; signal transduction]

Received September 3, 1999; revised version accepted October 26, 1999.

Rapamycin inhibits a conserved signaling cascade required for cell proliferation (Thomas and Hall 1997; Cardenas et al. 1998; Cutler et al. 1999). Rapamycin action is mediated by binding to the FKBP12 prolyl isomerase, and the FKBP12-rapamycin complex in turn inhibits conserved protein kinase homologs, Tor1 and Tor2 in yeast, and mTOR/FRAP/RAFT1 in mammalian cells (Heitman et al. 1991; Cafferkey et al. 1993; Kunz et al. 1993; Brown et al. 1994; Helliwell et al. 1994; Sabatini et al. 1994; Cardenas and Heitman 1995; Sabers et al. 1995; Zheng et al., 1995; Alarcon et al. 1996). The yeast Tor proteins and mammalian $\mathrm{mTOR}$ have intrinsic protein kinase activity (Brown et al. 1995; Brunn et al. 1997; Alarcon et al. 1999; Jiang and Broach 1999).

The TOR kinases are essential for viability and regulate translation initiation and cell cycle progression (Heitman et al. 1991; Kunz et al. 1993; Barbet et al. 1996). Depletion of TOR or exposure to rapamycin inhibits translation in yeast by destabilizing the initiation factor eIF4G (Berset et al. 1998). mTOR regulates translation in mammalian cells via p70 S6 kinase and the PHAS-I inhibitor of the CAP-binding protein eIF-4E (Graves et al. 1995; Lawrence and Abraham 1997). mTOR phosphorylates PHAS-I in vitro and regulates PHAS-I phosphorylation in vivo (Lin et al. 1995; von Manteuffel et al. 1996;

${ }^{7}$ Corresponding author.

E-MAIL carde004@mc.duke.edu; FAX (919) 684-5458.
Brunn et al. 1997; Burnett et al. 1998). Phosphorylation causes PHAS-I to release eIF-4E, which then interacts with eIF4G to form a productive 5'CAP-binding complex and initiate translation.

The yeast Tap42 protein and a homologous mammalian protein $\alpha 4$ have been implicated as targets of the TOR pathway. Tap42 is an essential protein that associates with protein phosphatase $2 \mathrm{~A}$ (PP2A) subunits and regulates translation initiation in yeast (Di Como and Arndt 1996). Rapamycin treatment or nutrient deprivation disassociates Tap42 from the PP2A subunits Sit4, Pph21, and Pph22. Tap42 is a phosphoprotein in vivo and the Tor2 kinase regulates Tap42 phosphorylation (Jiang and Broach 1999). The mammalian $\alpha 4$ protein is homologous to yeast Tap42 (Chen et al. 1998) and its association with PP2A is also perturbed by rapamycin (Murata et al. 1997; Inui et al. 1998).

The Tor kinases play a role in nutrient sensing in yeast and mammalian cells. In yeast, the TOR kinases regulate sporulation and autophagy (Zheng and Schreiber 1997; Noda and Ohsumi 1998). TOR also regulates the Npr1 protein kinase that is required for the stabilization or degradation of amino acid permeases in response to nutrients (Schmidt et al. 1998). Rapamycin represses transcription of rRNA and tRNA by inhibiting RNA polymerases I and III (Zaragoza et al. 1998), and inhibits ribosome biogenesis (Powers and Walter 1999). In the fission yeast Schizosaccharomyces pombe, rapamycin 
has no effect on vegetative growth, but blocks mating in response to nitrogen starvation (Weisman et al. 1997). In mammalian cells, the mTOR kinase is activated by amino acids (Hara et al. 1998; Xu et al. 1998; Kimball et al. 1999) and regulates autophagy in cultured hepatocytes (Shigemitsu et al. 1999).

Signaling cascades enable yeast cells to shift from the utilization of abundant levels of good nitrogen sources to either poorer nitrogen sources or limiting concentrations of good nitrogen sources (Magasanik 1992). Glutamine synthetase plays a central role in nitrogen metabolism by converting ammonium to glutamine (Mitchell and Magasanik 1983). Intracellular glutamine is sensed by a pathway involving the Ure2 repressor, which binds and inhibits glutamine synthetase (Gln1) and the transcriptional activator Gln3 (Courchesne and Magasanik 1988; Coschigano and Magasanik 1991; Xu et al. 1995; Blinder et al. 1996). When cells are shifted to poor or limiting nitrogen sources, intracellular glutamine decreases, Ure2 is inactivated, and glutamine synthetase and Gln3 are activated, increasing glutamine and inducing nitrogen utilization genes. Gln3 activates genes encoding glutamine synthetase (Gln1), glutamate synthase (Glt1), glutamate dehydrogenase (Gdh1 and Gdh2), permeases for nitrogenous compounds (Gap1 and Mep2), enzymes involved in nitrogen source metabolism (Dal3 and Put1), and transcription factors that regulate gene expression (Dal80 and Dal82) (Mitchell and Magasanik 1984; Minehart and Magasanik 1991; Stanbrough et al. 1995). How cells sense nitrogen, how glutamine regulates Ure2, and how Ure2 regulates Gln3 are not known.

Gene expression analysis with yeast genome arrays reveals that rapamycin has profound effects on gene transcription, inducing nitrogen catabolite-repressed genes regulated by Gln3 and Ure2 and globally repressing ribosomal protein expression. Moreover, mutations in genes encoding nitrogen source regulatory proteins, including Ure2, Gln3, Npr1, and Npi1, were found to modulate rapamycin action. We show that Ure2 is a phosphoprotein in vivo whose phosphorylation state is regulated by nutrients and TOR kinase. In conclusion, the TOR kinases function in a signaling cascade that detects nitrogen sources and regulates gene expression.

\section{Results}

Rapamycin induces transcription of nitrogen

catabolite-repressed genes and represses

expression of ribosomal proteins

The TOR cascade is known to regulate translation in yeast and mammalian cells. Here, we tested whether the TOR cascade also regulates gene transcription. For this purpose, yeast cells were exposed to rapamycin and mRNA was isolated and hybridized to yeast whole-genome arrays. This analysis revealed that the expression of multiple genes was altered by rapamycin. Most importantly, a set of genes known to be transcriptionally induced by Gln 3 was increased from 5 - to 50-fold following rapamycin exposure (Table 1). These genes have been characterized previously as the nitrogen catabolite-repressed genes, which are repressed in the presence of abundant rich nitrogen sources by Ure2-dependent inhibition of $\mathrm{Gln} 3$, and induced in a Gln3-dependent fashion when cells are grown with limiting quantities of good nitrogen sources (glutamine and ammonia) or poor nitrogen sources (proline and urea) (Magasanik 1992). These genes encode nitrogen metabolizing enzymes, including glutamate dehydrogenase (Gdh1 and Gdh2), plasma membrane permeases for nitrogenous compounds, including the general amino acid permease (Gap1), the high affinity ammonium permease (Mep2), and the high affinity proline permease (Put4), and enzymes involved in the catabolism of nitrogen sources, including allantoin utilization (Dall and Dal3), urea degradation (Dur1,2), and GABA catabolism (Uga1) (Table 1).

To confirm these findings obtained by hybridization to whole genome arrays, mRNA was isolated from cells exposed to rapamycin for $0,15,30,60$, or $120 \mathrm{~min}$ and subjected to Northern blot analysis (Fig. 1). This analysis provided independent confirmation that the GAP1, $M E P 2$, and GLN1 genes are induced by rapamycin, and also revealed that gene induction occurs rapidly following rapamycin addition. Other genes known to be induced by nutrient limitation, such as $S N Z 1$, were induced by rapamycin only at later time points (Fig. 1). In contrast to rapamycin, the protein synthesis inhibitor cycloheximide did not affect GAP1, MEP2, or GLN1 expression (Fig. 1). These findings support a model in which the TOR cascade regulates nitrogen source utilization gene expression in response to nutrients.

Consistent with a recent report (Powers and Walter 1999), analysis of gene expression with whole-genome arrays revealed a marked and global repression of the vast majority of the genes encoding cytoplasmic, but not mitochondrial, ribosomal proteins (Table 2). Northern blot analysis confirmed that rapamycin represses expression of two specific cytoplasmic ribosomal proteins (Rp19A and Rps26) (Fig. 1). In contrast, cycloheximide treatment modestly stimulated the transcription of these ribosomal protein genes (Fig. 1). These observations confirm that the TOR cascade functions to regulate transcription of ribosomal components in addition to the known effects of the TOR-signaling cascade on translation.

\section{Proteins that regulate utilization of nitrogen sources play a role in TOR signaling}

Next, we sought to establish whether the ability of the TOR cascade to regulate Ure 2 and Gln3-regulated genes results in physiological alterations in rapamycin action. gln3 mutant strains were partially resistant to rapamycin, whereas ure2 mutant strains were rapamycin hypersensitive (Fig. 2A). The fact that the ure2 and gln3 mutations confer opposite phenotypes is in accord with their known effects on Gln3-mediated gene expression, namely that ure2 mutations derepress Gln3-regulated genes, whereas gln 3 mutations impair gene induction by 
Table 1. Rapamycin induces expression of nitrogen catabolite repressed genes

\begin{tabular}{|c|c|c|}
\hline Gene & Fold induction & Gene product/function \\
\hline \multicolumn{3}{|l|}{ Permeases } \\
\hline MEP2 & 46.2 & high-affinity ammonium permease \\
\hline$D A L 5$ & $19.2^{\mathrm{a}}$ & allantoate and ureidosuccinate permease \\
\hline GAP1 & 7.3 & general amino acid permease \\
\hline$D A L 4$ & $5.1^{\mathrm{a}}$ & allantoin permease \\
\hline PUT4 & $4.5^{\mathrm{a}}$ & high affinity proline permease \\
\hline CAN1 & 4.3 & arginine permease \\
\hline \multicolumn{3}{|c|}{ General catabolism } \\
\hline GDH2 & 5.0 & glutamate dehydrogenase (NAD) \\
\hline GLT1 & 3.0 & glutamate synthase \\
\hline GDH1 & 1.4 & glutamate dehydrogenase (NADP) \\
\hline GLN1 & 0.0 & glutamine synthetase \\
\hline \multicolumn{3}{|c|}{ Specific catabolism } \\
\hline DUR1,2 & 16.0 & urea degradation \\
\hline$D A L 3$ & $15.7^{\mathrm{a}}$ & allantoin utilization (ureidoglycolate hydrolase) \\
\hline PUT1 & $11.7^{\mathrm{a}}$ & proline catabolism \\
\hline DAL1 & $7.9^{\mathrm{a}}$ & allantoin utilization (allantoinase) \\
\hline$U G A 1$ & 5.6 & GABA catabolism \\
\hline PUT2 & 2.8 & proline catabolism \\
\hline$D A L 7$ & $1.6^{\mathrm{a}}$ & allantoin degradation (malate synthetase) \\
\hline$D A L 2$ & $1.5^{\mathrm{a}}$ & allantoin utilization (allantoicase) \\
\hline \multicolumn{3}{|c|}{ Transcriptional regulation } \\
\hline DAL80/UGA43 & 8.2 & transcriptional repressor \\
\hline GAT1/NIL1 & 3.1 & transcriptional activator \\
\hline$D A L 82$ & 2.5 & transcriptional repressor \\
\hline \multicolumn{3}{|c|}{ Central regulators } \\
\hline GLN3 & $2.0^{\mathrm{a}}$ & transcriptional activator \\
\hline URE2 & 2.2 & inhibitor of Gln 3 and glutamine synthetase \\
\hline NPR1 & 4.2 & serine/threonine kinase \\
\hline
\end{tabular}

Strain MLY41 was grown to early exponential phase and treated with or without $0.2 \mu \mathrm{g} / \mathrm{ml}$ rapamycin for 2 hr. Cells were harvested and poly(A) RNA was isolated and processed for yeast genome analysis. Note that the results shown are fold of gene induction (above) or repression (Table 2) observed in the rapamycin-treated sample using the untreated sample as the baseline. Note that maximal induction of the GLN1 gene occurs at $1 \mathrm{hr}$ after treatment (see Fig. 1), and at $2 \mathrm{hr}$ expression has returned to the original uninduced level.

${ }^{a}$ No signal detected in untreated cells.

nitrogen limitation (Magasanik 1992). A ure2 gln3 double mutant exhibited the rapamycin-resistant phenotype conferred by the gln 3 single mutation (not shown), indicating that the effects of the $g \ln 3$ mutation are epistatic to the ure 2 mutation, in accord with a linear pathway in which Ure2 inhibits Gln3.

To further test whether Ure2 is a component of the TOR cascade, we addressed whether the ure2 mutation alters the level of rapamycin resistance conferred by TOR2, TOR1, or fpr1 mutations. As shown in Figure 2B, the ure 2 mutation significantly reduced the level of rapamycin resistance conferred by the dominant TOR2-1 or TOR1-4 mutations. Because rapamycin can only inhibit the wild-type Tor1 kinase in the ure2 TOR2-1 mutant cells, or the wild-type Tor2 kinase in the ure2 TOR1-4 mutant cells, the simplest explanation is that both Tor1 and Tor2 are required for rapamycin resistance in cells lacking Ure2. In comparison, the ure2 mutation had no effect on rapamycin resistance conferred by FKBP12 mutations, because in these mutant cells, rapamycin is unable to interact with TOR (Fig. 2B).
The level of rapamycin resistance or hypersensitivity conferred by gln3 and ure2 mutations was found to be similar to that afforded by mutations affecting the Npr1 kinase and Npil ubiquitin ligase (Fig. 2A), which function in a nutrient-regulated TOR pathway controlling nutrient permeases (Schmidt et al. 1998). A kinase-inactive Npr1 mutant did not restore rapamycin sensitivity of npr1 mutants, indicating kinase activity is important for function (not shown). In contrast, the npil mutation conferred rapamycin hypersensitivity (Fig. 2A), and suppressed rapamycin resistance conferred by npr1 or TOR mutations (not shown). Mutations in permeases regulated by Npr1 or Npil, including Gap1, Mep1, Mep2, and Mep3, had little or no effect on rapamycin action (data not shown); hence, other Nprl and Npil targets in the Tor pathway remain to be identified. Drug import assays revealed no effect of the gln3 or ure2 mutations on rapamycin import (data not shown), and taken together, these findings indicate altered rapamycin sensitivity is not attributable to alterations in drug uptake. 


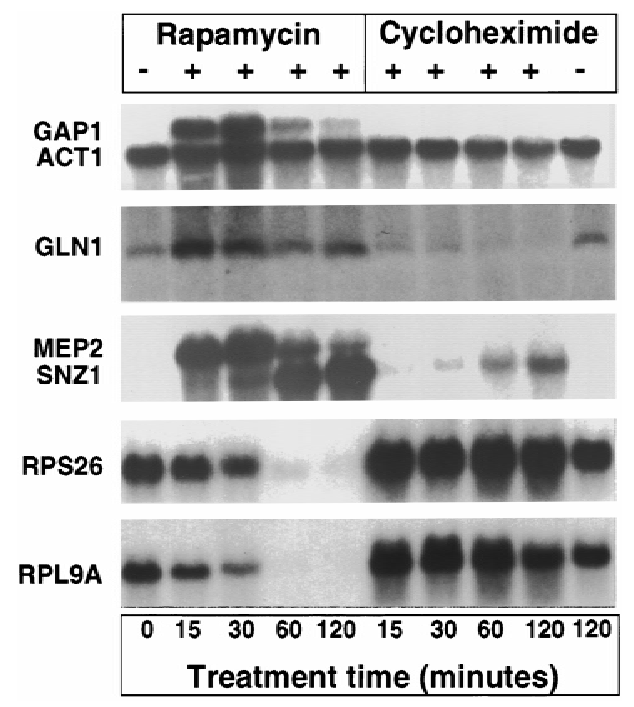

Figure 1. Rapamycin induces and represses gene expression. The wild-type yeast strain MLY41 was grown to early exponential phase, and treated with or without $0.2 \mu \mathrm{g} / \mathrm{ml}$ rapamycin or $10 \mu \mathrm{g} / \mathrm{ml}$ cycloheximide for $15,30,60$, and $120 \mathrm{~min}$, as indicated. RNA was prepared and analyzed by Northern blot with radioactive probes that hybridize to the genes indicated at left. Hybridization to the actin gene (ACT1) served as a loading control.

Tor regulates phosphorylation of nitrogen source regulator Ure2

The Ure2, Gln3, Npr1, and Npil nitrogen source regulators could alter sensitivity to rapamycin by regulating Tor 1 or Tor 2 expression, or as regulators or effectors of the TOR cascade. By Western blot analysis, the ure2, gln3, npr1, and npi1 mutations did not alter Tor1 or Tor2 expression (not shown).

Tor inhibition had only modest effects on GLN3 and URE2 gene expression, suggesting that rapamycin exerts a posttranscriptional effect. Next, we tested the hypothesis that Ure2 is a phosphoprotein regulated by the TOR pathway. By Western blot analysis with specific polyclonal antisera, the Ure2 protein migrated as either a single species, or, in some cases, as two species, in SDSPAGE analysis of total protein extracts from vegetative cells grown in rich medium (Fig. 3). Importantly, treatment with $0.2 \mu \mathrm{g} / \mathrm{ml}$ rapamycin led to a rapid increase in the electrophoretic mobility of the faster-migrating form of Ure2, concomitant with the disappearance of the slower-migrating form of Ure2 (Fig. 3A,B). The effect of rapamycin on the mobility of Ure2 was blocked in an fpr1 rapamycin-resistant mutant (Fig. 3A,B). When cells growing in rich medium were shifted to SLAD medium limiting for ammonium, a similar and rapid increase in the electrophoretic mobility of Ure2 was observed (Fig. $3 \mathrm{~A})$. When protein extracts from cells grown in rich medium in the absence of rapamycin were treated with alkaline phosphatase, the mobility of the Ure2 protein was increased to an extent similar to that observed with rapamycin treatment or nutrient limitation (Fig. 3B). We conclude that Ure2 is a phosphoprotein that is rapidly de- phosphorylated following exposure to rapamycin or nitrogen limitation.

Because the Tor kinase is known to regulate association of the Tap42 regulatory subunit with protein phosphatase 2A (Di Como and Arndt 1996; Jiang and Broach 1999|, we addressed whether Tor regulates Ure2 via Tap42. When a strain expressing a Tap42-11 conditional mutant was shifted from $24^{\circ} \mathrm{C}$ to $37^{\circ} \mathrm{C}$, analysis of gene expression by hybridization to whole genome arrays revealed no induction of the nitrogen utilization genes regulated by the Tor pathway (not shown). The tap42-11 mutation confers partial resistance to rapamycin (DiComo and Arndt 1996). However, by Northern blot analysis, rapamycin still induced expression of the GAP1 and MEP2 genes, and repressed expression of the RPS26 ribosomal protein gene, in a tap42-11 mutant strain compared with the isogenic TAP42 wild-type strain at the permissive growth temperature (not shown). These observations suggest that the Tor pathway may not regulate Ure 2 and Gln3 via the Tap42 regulatory subunit of PP2A.

\section{Discussion}

The TOR kinases are the targets of rapamycin in complex with the cellular protein FKBP12, and both TOR and FKBP12 are conserved from yeast to man. The TOR kinases regulate translation via divergent mechanisms in mammalian cells (PHAS-I, p70 S6 kinase) and yeast cells (eIF4G stability). Recent studies have revealed that the TOR kinase pathway also regulates cellular responses to nutrients. Here, we examined whether the Tor pathway regulates gene expression in yeast cells.

Table 2. Rapamycin represses expression of ribosomal proteins

\begin{tabular}{lrl}
\hline Gene & Fold change & \multicolumn{1}{c}{ Gene product } \\
\hline $\begin{array}{l}\text { Ribosomal } \\
\text { proteins }\end{array}$ & & \\
$R P L 9 A$ & -43.2 & ribosomal protein YL11 \\
$R P S 26 A$ & -22.1 & ribosomal protein S26 \\
$R P L 6 B$ & -16.6 & ribosomal protein YL8B \\
RPL10E & -6.8 & 60S ribosomal protein P0 \\
CRY2 & -6.5 & ribosomal protein CRY1 (rp59) \\
RPS18B & -6.1 & ribosomal protein S18 \\
URP1 & -5.4 & ribosomal protein URP1 \\
RPS28B & -5.2 & ribosomal protein rp28 \\
$R P S 5$ & -4.6 & ribosomal protein S5 \\
$R P S 3$ & -3.7 & ribosomal protein RPS3 \\
$R P S 26 B$ & -3.4 & ribosomal protein S26 \\
$R P S 28 A$ & -3.2 & ribosomal protein S28 \\
$R P S 25$ & -2.5 & ribosomal protein S21 \\
$R P L 37 A$ & -2.4 & ribosomal protein L25 \\
$R P S 33 B$ & 0.0 & ribosomal protein S33 (YL27) \\
$R P L 4 B$ & 9.9 & ribosomal protein L4B (YL5) \\
Mitochondrial & & \\
ribosomal & & \\
proteins & & \\
$M R P L 27$ & 0.0 & MRPL27 \\
MRPL39 & 1.5 & MRPL39 \\
MRPL33 & 1.6 & MRPL33 \\
MRPL36 & 1.8 & MRPL36 \\
\hline
\end{tabular}


A

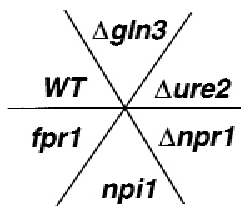

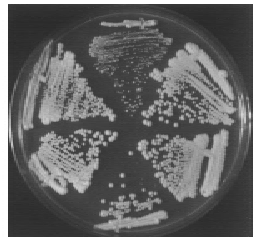

0

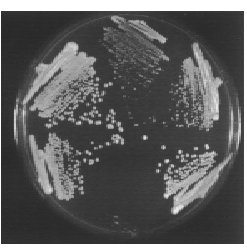

10 $\mathrm{ng} / \mathrm{ml}$ rapamycin

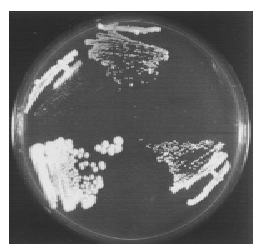

50

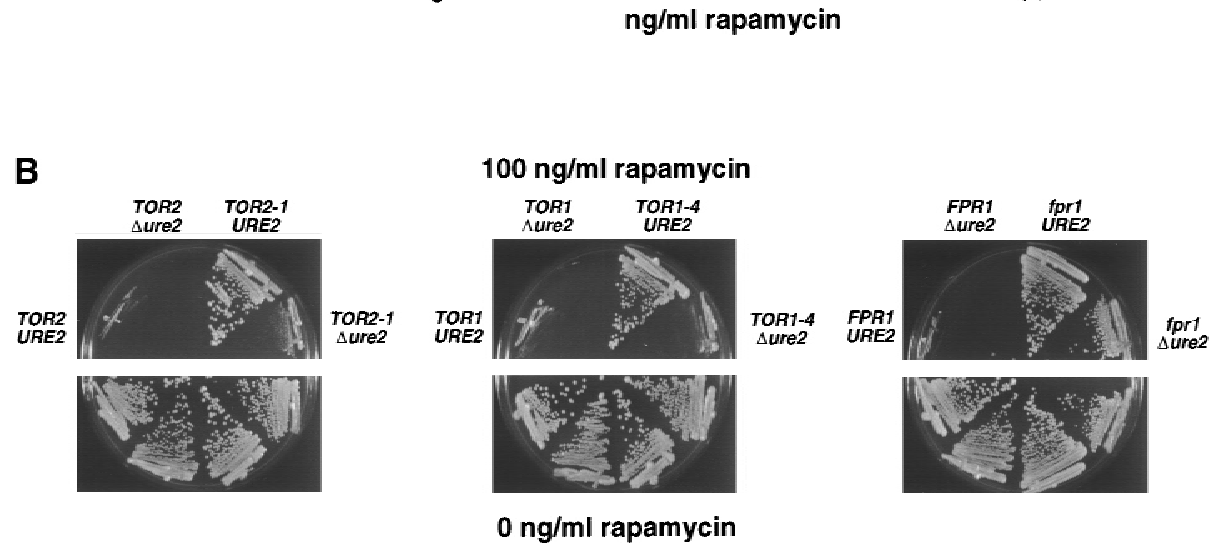

Figure 2. Mutations affecting nitrogen-source utilization alter rapamycin toxicity. (A) Isogenic wild-type (MLY41) and $\Delta$ gln3 (MLY139), Aure2 (MLY140a), Anpr1 (MLY54a), npi1 (MLY141a), and fpr1 (MLY88) mutant strains were grown on YPD medium containing 0,10 , or $50 \mathrm{ng} / \mathrm{ml}$ rapamycin and incubated for 3 days at $30^{\circ} \mathrm{C}$. (B) Isogenic wild-type (MLY41) and $\Delta$ ure2 (MLY140a),

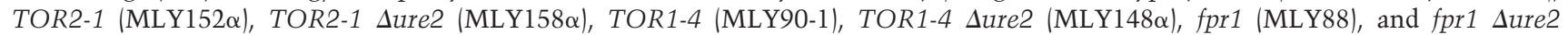
(MLY146a) mutant strains were grown on YPD medium containing 0 or $100 \mathrm{ng} / \mathrm{ml}$ rapamycin and incubated for 3 days at $30^{\circ} \mathrm{C}$.

Whole-genome array analysis revealed that inhibiting the Tor kinase with rapamycin has profound effects on the transcription of many yeast genes. Rapamycin rapidly induces expression of nitrogen-source utilization genes (nitrogen catabolite-repressed genes) known to be regulated by the repressor Ure2 and the transcription factor $G \ln 3$. In contrast, another protein synthesis inhibitor, cycloheximide, does not induce the nitrogen catabolite-repressed genes (Fig. 1). Rapamycin also globally represses expression of ribosomal proteins, in accord with recent reports that rapamycin inhibits ribosome biogenesis and rRNA and tRNA gene expression (Zaragoza et al. 1998; Powers and Walter 1999).

We have found that nitrogen-source regulators play a general role in rapamycin toxicity in yeast. Mutations in the gene encoding the Ure2 repressor, the Gln3 transcriptional activator, and the Nprl kinase and Npil ubiquitin ligase confer either rapamycin resistance $(g \ln 3$, npr1) or hypersensitivity (ure2, npi1). We show that the Ure2 protein is a phosphoprotein. Ure2 is rapidly dephosphorylated following nutrient limitation or inhibition of the TOR kinases with rapamycin, with a time course similar to induction of the Ure2-repressed genes by rapamycin. As outlined in Figure 4, our findings support a model in which the TOR kinase pathway responds to nutrients, and regulates nitrogen-utilization gene expression by regulating the phosphorylation of Ure2 and thereby modulating interaction with, and inhibition of, Gln3. Such a model is analogous to the role of Tor in regulating phosphorylation and interaction of Tap42 with PP2A in yeast cells, of the Tap 42 homolog $\alpha 4$ regulator of PP2A in mammalian cells, and of the PHAS-I inhibitor of eIF4E in mammalian cells. Recent studies have revealed a similar role for the Tor kinases in regulating nutrient permease stabilization and degradation by the Nprl kinase (Schmidt et al. 1998). Mutations in Gln3 and Npr1 nitrogen-source regulators result in relative, but not absolute, rapamycin resistance, indicating that these mutations likely represent two of several independent signaling branches downstream of the TOR kinase (see Fig. 4), such that mutation of any one branch confers only partial drug resistance.

Activation of TOR and implications for rapamycin action in mammalian cells

Our studies implicate a role for the TOR-signaling cascade in sensing nitrogen sources in yeast cells. How the TOR kinases are activated is not understood, but recent findings in both yeast and mammalian cells suggest possible models involving the sensing of amino acids. Rapamycin has been thought to inhibit signaling pathways required for mammalian cells to respond to growth factors, such as interleukin-2 and insulin (Kuo et al. 1992; Price et al. 1992). However, rapamycin also inhibits response to nutrients, such as amino acids, which may activate a TOR-signaling cascade that functions in parallel with growth factor-signaling cascades to promote cell proliferation. For example, the p70 S6 kinase is activated by the mTOR-signaling pathway in response to either glutamine or leucine (Fox et al. 1998; Hara et al. 1998; Xu et al. 1998; Kimball et al. 1999). How these amino acids are sensed by mammalian cells is not yet 


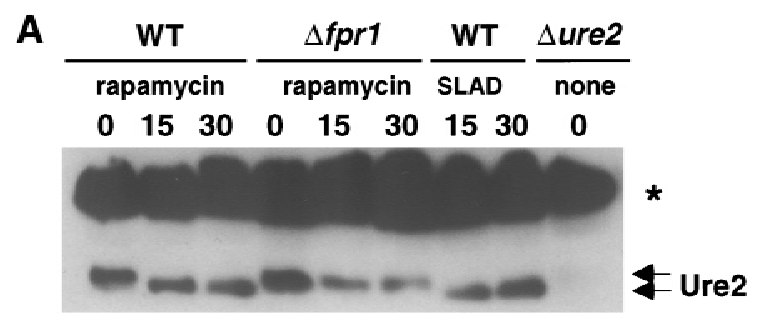

B

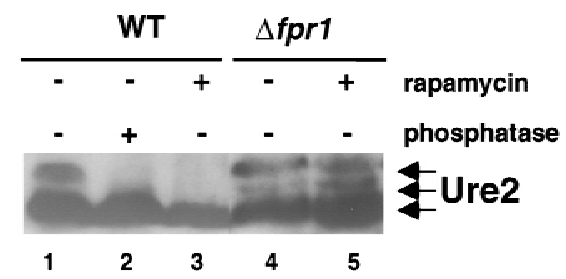

Figure 3. Tor and nutrients regulate the phosphorylation state of Ure2. (A) The isogenic wild-type (WT, strain MLY41) and $\Delta$ fpr1 mutant strain (strain MLY88) were grown to early exponential phase $\left(\mathrm{OD}_{600}=0.4\right)$ in YPD medium and treated with $0.2 \mu \mathrm{g} / \mathrm{ml} \mathrm{rapamycin} \mathrm{for} 0,15$, and $30 \mathrm{~min}$. Alternatively, the isogenic wild-type strain MLY41 was grown as above, washed with SLAD ammonium limiting medium, and then incubated in SLAD medium for 15 and $30 \mathrm{~min}$. Total cell extracts were prepared and $100 \mu \mathrm{g}$ of protein analyzed by SDS-PAGE $(12.5 \%)$ and Western blot with Ure2 antibodies. Cell extract from a sure2 mutant strain (strain MLY140a) was included as a control for antisera specificity. (Arrows) The migration position of phosphorylated isoforms of Ure2; $\left({ }^{*}\right)$ a protein that crossreacts nonspecifically with the anti-Ure 2 antisera. $(B)$ Protein cell extract from wild-type strain MLY41 was incubated with 4 units of alkaline phosphatase for $30 \mathrm{~min}$ at $37^{\circ} \mathrm{C}$. Protein extracts from rapamycin treated or untreated wild-type strain (MLY41) or the $\Delta f p r 1$ mutant strain (MLY88), as indicated, were mock incubated and loaded in lanes 1, 3, 4, and 5 to compare the mobility of phosphorylated and dephosphorylated Ure2. Note that cell extracts in $A$ were analyzed in $12.5 \%$ SDS-polyacrylamide gels; the extracts in $B$ were fractionated in $10 \%$ SDS-PAGE for a longer period of time, which could explain the greater separation of phosphorylated and dephosphorylated Ure2 observed in $B$.

known. Activation of p70 S6 kinase by the Tor pathway is inhibited in cells expressing conditional tRNA synthetase mutants, or in which tRNA synthetases are inhibited with amino acid alcohols. Thus, charged tRNAs may activate mTOR, or uncharged tRNAs might inhibit mTOR (Iiboshi et al. 1999b).

Rapamycin may have novel clinical indications as a chemotherapy agent for rapamycin-sensitive tumors, which include glioblastoma and prostate carcinoma (Dilling et al. 1994; Shi et al. 1995; Hosoi et al. 1999; Louro et al. 1999). The spectrum of rapamycin action might also be extended by applying insights derived from basic studies on rapamycin-sensitive signaling cascades. For example, the enzyme asparaginase is used to treat acute lymphoblastic leukemia, and exogenous asparaginase sensitizes cultured mammalian cells to rapamycin, possibly by reducing extracellular levels of glutamine and asparagine and thereby impairing TOR-dependent cell proliferation (Iiboshi et al. 1999a). Clearly, much still remains to be learned about TOR regulation of nutrient signaling, but studies in yeast continue to provide insights into conserved pathways as targets for therapy.

\section{Materials and methods}

RNA isolation and Northern analysis

Strain MLY41a was grown to an $\mathrm{OD}_{600}$ of 0.4 and treated or not treated with $0.2 \mu \mathrm{g} / \mathrm{ml}$ rapamycin for various periods of time as indicated in figure legends. Cells were harvested by centrifugation, washed with DEPC-treated water, and immediately frozen in an ethanol dry-ice bath. Total RNA was isolated from 50 $\mathrm{OD}_{600}$ units of cells by use of the RNeasy Mini kit from Qiagen, according to the manufacturer's instructions. RNA was quantified by spectrophotometry, actin mRNA level was detected by autoradiography in an initial gel, and equal amounts of RNA normalized to the level of the actin message were loaded on $5 \%$ formaldehyde and $1.2 \%$ agarose gels. Gels were electrophoresed in $20 \mathrm{~mm}$ MOPS (pH 7.0), $5 \mathrm{~mm} \mathrm{NaOAc}$, and 1 mm EDTA. RNA was transfered to Nytran Plus membranes (Schleicher \& Schuell) and cross-linked by UV irradiation. The membranes were then incubated for $2 \mathrm{hr}$ at $42^{\circ} \mathrm{C}$ in prehybridization solution $(5 \times \mathrm{SSC}$, $5 \times$ Denhardt's solution, $50 \%$ formamide, $0.2 \%$ SDS, $10 \mathrm{mg} / \mathrm{ml}$ salmon sperm DNA) and the ${ }^{32} \mathrm{P}$-labeled radioactive probe was added and hybridized overnight at $42^{\circ} \mathrm{C}$. The membranes were washed twice in $2 \times \mathrm{SSC}$ at $42^{\circ} \mathrm{C}$ and four times at $62^{\circ} \mathrm{C}$ in $2 \times$ SSC, $0.2 \%$ SDS. RNA was visualized by autoradiography. Northern probes were labeled with $\left[\alpha-{ }^{32} \mathrm{P}\right] \mathrm{dCTP}$ with the random primer labeling kit from Stratagene. Quantitation of Northern blots was performed on a Molecular Dynamics Storm 860 PhosphorImager.

\section{Gene chip hybridization and analysis}

Total RNA preparation for gene array analysis was scaled up for $200 \mathrm{OD}_{600}$ of cells and performed as above. Poly(A) mRNA was isolated from total RNA with a mini-oligo (dT) cellulose spin column kit from 5 prime-3 prime Inc. (Boulder, CO). Poly(A) mRNA was used to prepare cDNA with the Superscript Choice System (GIBCO BRL) and biotinylated cRNA was synthesized

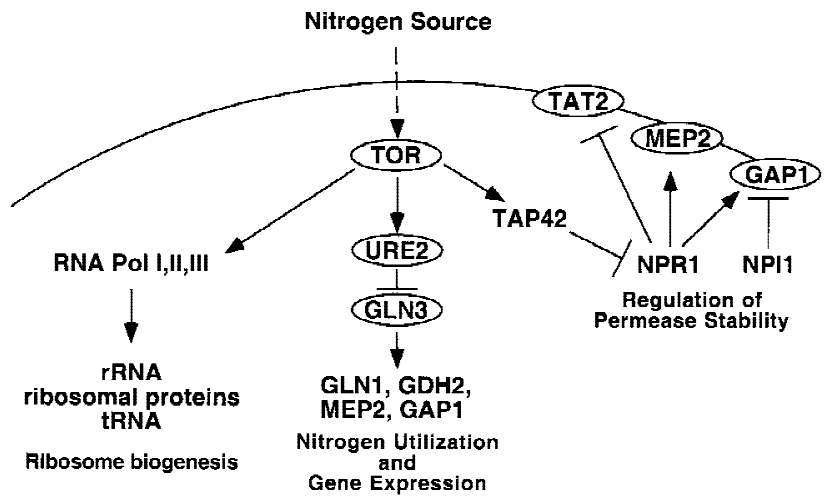

Figure 4. The TOR signaling cascade regulates gene expression in response to nutrients. The Tor proteins are activated by nutrients, and regulate the expression of genes involved in the utilization of nitrogen sources via Ure2 and Gln3, ribosome biogenesis by RNA polymerases, and amino acid permease stability. 
with Biotin-11-CTP and the Megascript T7 Kit (Ambion). Biotinylated cRNA was fragmented by incubation at $94^{\circ} \mathrm{C}$ for 35 min in $40 \mathrm{~mm}$ Tris acetate (pH 8.1), $100 \mathrm{~mm} \mathrm{KOAc}$, and $30 \mathrm{~mm}$ $\mathrm{MgOAc}$. Free unincorporated Biotin nucleotides were eliminated with the RNeasy Mini Kit (Qiagen). Biotinyated cRNA was hybridized to the gene chip arrays at $45^{\circ} \mathrm{C}$ overnight. Hybridization, washing, and streptavidin staining were performed in the Affymetrix Gene Chip fluidics station 400. Gene chips were scanned in a Hewlett-Packard G2500A Gene array scanner and expression data was analyzed with the Affymetrix Gene Chip analysis suite version 3.1.

\section{Media and strains}

Yeast media were prepared as described previously (Sherman 1991; Gimeno et al. 1992). Rapamycin and cycloheximide were added to the media from concentrated stock solutions in $90 \%$ ethanol/10\% Tween 20 and water, respectively. Yeast transformations were performed by the lithium acetate method (Schiestl et al. 1993). Unless noted otherwise, mutant yeast strains were constructed by PCR-mediated gene disruptions with the G418-resistance gene cassette derived from template plasmid pFA6-kanMX2 as described (Table 3; Wach et al. 1994). MLY88 $\alpha$ and MLY90-1 were generated as spontaneous resistant mutants of strain MLY40 on YPD medium containing $0.2 \mu \mathrm{g} /$ $\mathrm{ml}$ rapamycin. The rapamycin-resistant mutation in strain MLY88 $\alpha$ was complemented by the introduction of a plasmid bearing the wild-type FPR1 gene (pYJH23). Strain MLY90-1 was shown to harbor the TOR1-4 mutation by meiotic segregation of the rapamycin-resistance phenotype opposite a tor $1:: L E U 2$ deletion mutation following a genetic cross. MLY152 a/ $\alpha$ was created by PCR mutagenesis of strain MLY40 $\alpha$ and the presence of the Ser-1975-Ile mutation in the TOR2 gene confirmed by DNA sequencing. Strains MLY158 $\alpha$, MLY148 $\alpha$, and MLY146 $\alpha$ were constructed by mating strain MLY140a with strains MLY152 $\alpha$, MLY90-1, and MLY88 $\alpha$, respectively, followed by sporulation and dissection of tetrads.

Protein extracts, alkaline phosphatase treatment, and Western analysis

Cells harvested and frozen as indicated above were resuspended in ice-cold lysis buffer $\left(20 \mathrm{~mm} \mathrm{KPO}_{4}\right.$ at $\mathrm{pH} 7.2,1 \mathrm{~mm}$ EDTA, 1

Table 3. Strain list

\begin{tabular}{|c|c|c|}
\hline Strain & Genotype & Source \\
\hline MLY41 & ¿1278b MATa ura3-52 & Lorenz (1997) \\
\hline MLY40 & 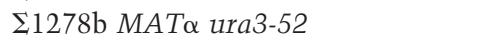 & Lorenz (1997) \\
\hline MLY88 & $\Sigma 1278 b$ MAT $\alpha$ ura3-52 fpr1 & this study \\
\hline MLY139a & 乏1278b MATa ura3-52 Agln3::G418 & Lorenz (1998) \\
\hline MLY140a & 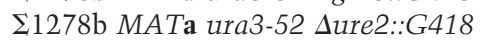 & Lorenz (1998) \\
\hline MLY54a & 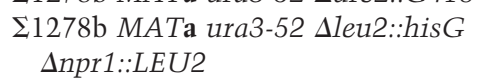 & Lorenz (1998) \\
\hline MLY141a & ¿1278b MATa ura3-52 npil & Lorenz (1998) \\
\hline MLY $152 \alpha$ & $\begin{array}{l}\text { ¿1278b MATa ura3-52 TOR2-1 } \\
\text { (Ser-1975-Ile) }\end{array}$ & this study \\
\hline MLY158 $\alpha$ & 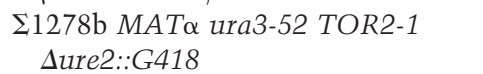 & this study \\
\hline MLY90-1 & 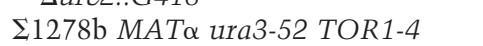 & this study \\
\hline MLY $148 \alpha$ & 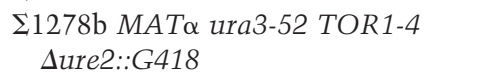 & this study \\
\hline MLY146 $\alpha$ & 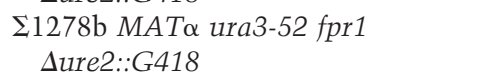 & this study \\
\hline
\end{tabular}

mM EGTA, 0.5\% Triton X-100, 25 mm $\beta$-glycerophosphate, 25 $\mathrm{mm} \mathrm{NaF}, 100 \mu \mathrm{Na}_{3} \mathrm{VO}_{4}, 1 \mathrm{~mm}$ DTT, $1 \mathrm{~mm}$ PMSF, $1 \mathrm{~mm}$ benzamidine, $1 \%$ aprotinin, $1 \mu \mathrm{g} / \mathrm{ml}$ pepstatin, $100 \mu \mathrm{M}$ leupeptin). Cells were lyzed at $4{ }^{\circ} \mathrm{C}$ with glass beads by five strokes of $1 \mathrm{~min}$ each in a bead beater (Biospec) with cooling for $1 \mathrm{~min}$ between strokes. Following centrifugation, protein was quantitated by Bradford assay (Amersham) and $100 \mu \mathrm{g}$ of protein extract was loaded onto SDS-polyacrylamide gels. Proteins were detected by Western blot analysis with rabbit polyclonal antisera against Ure2 (Wickner 1994) and ECL plus detection (Amersham). For alkaline phosphatase treatment, $100 \mu \mathrm{g}$ of protein extract were adjusted to $2 \mathrm{mM} \mathrm{MgCl}_{2}$ and 4 units of alkaline phosphatase (Boehringer Mannheim) were added and samples incubated at $37^{\circ} \mathrm{C}$ for $30 \mathrm{~min}$. Extracts were mixed with protein sample buffer boiled for 4 min and analyzed by Western blot as indicated above.

\section{Acknowledgments}

We thank Helena Abushamaa for assistance with genome array analysis, Xuewen Pan for advice on Northern blots, and Dr. Reed Wickner for his generous gift of Ure2 protein antiserum. M.E.C. dedicates this paper to Dr. Wilhelm Hansberg for early inspiration. This work was supported by KO1 award CA77075 from the National Cancer Institute (to M.E.C.) and RO1 award AI41937 from The National Institute of Allergy and Infectious Diseases (to J.H. and M.E.C.). J.H. is an associate investigator of the Howard Hughes Medical Institute.

The publication costs of this article were defrayed in part by payment of page charges. This article must therefore be hereby marked "advertisement" in accordance with 18 USC section 1734 solely to indicate this fact.

\section{References}

Alarcon, C.M., M.E. Cardenas, and J. Heitman. 1996. Mammalian RAFT1 kinase domain provides rapamycin-sensitive TOR function in yeast. Genes \& Dev. 10: 279-288.

Alarcon, C.M., J. Heitman, and M.E. Cardenas. 1999. Protein kinase activity and identification of a toxic effector domain of the target of rapamycin TOR proteins in yeast. Mol. Biol. Cell 10: 2531-2546.

Barbet, N.C., U. Schneider, S.B. Helliwell, I. Stansfield, M.F. Tuite, and M.N. Hall. 1996. TOR controls translation initiation and early G1 progression in yeast. Mol. Biol. Cell 7: 2542.

Berset, C., H. Trachsel, and M. Altmann. 1998. The TOR /target of rapamycin) signal transduction pathway regulates the stability of translation initiation factor eIF4G in the yeast Saccharomyces cerevisiae. Proc. Natl. Acad. Sci. 95: 42644269.

Blinder, D., P.W. Coschigano, and B. Magasanik. 1996. Interaction of the GATA factor Gln3p with the nitrogen regulator Ure2p in Saccharomyces cerevisiae. J. Bacteriol. 178: 47344736.

Brown, E.J., M.W. Albers, T.B. Shin, K. Ichikawa, C.T. Keith, W.S. Lane, and S.L. Schreiber. 1994. A mammalian protein targeted by G1-arresting rapamycin-receptor complex. $\mathrm{Na}$ ture 369: 756-759.

Brown, E.J., P.A. Beal, C.T. Keith, J. Chen, T.B. Shin, and S.L. Schreiber. 1995. Control of p70 S6 kinase by kinase activity of FRAP in vivo. Nature 377: 441-446.

Brunn, G.J., C.C. Hudson, A. Sekulic, J.M. Williams, J. Hosoi, P.J. Houghton, J. J.C. Lawrence, and R.T. Abraham. 1997. 
Phosphorylation of the translational repressor PHAS-I by the mammalian target of rapamycin. Science 277: 99-101.

Burnett, P.E., R.K. Barrow, N.A. Cohen, S.H. Snyder, and D.M. Sabatini. 1998. RAFT1 phosphorylation of the translational regulators p70 S6 kinase and 4E-BP1. Proc. Natl. Acad. Sci. 95: 1432-1437.

Cafferkey, R., P.R. Young, M.M. McLaughlin, D.J. Bergsma, Y. Koltin, G.M. Sathe, L. Faucette, W.-K. Eng, R.K. Johnson, and G.P. Livi. 1993. Dominant missense mutations in a novel yeast protein related to mammalian phosphatidylinositol 3-kinase and VPS34 abrogate rapamycin cytotoxicity. Mol. Cell. Biol. 13: 6012-6023.

Cardenas, M.E. and J. Heitman. 1995. FKBP12-rapamycin target TOR2 is a vacuolar protein with an associated phosphatidylinositol-4 kinase activity. EMBO I. 14: 5892-5907.

Cardenas, M.E., A. Sanfridson, N.S. Cutler, and J. Heitman. 1998. Signal-transduction cascades as targets for therapeutic intervention by natural products. Trends Biotechnal. 16: $427-433$.

Chen, J., R.T. Peterson, and S.L. Schreiber. 1998. Alpha 4 associates with protein phosphatases $2 \mathrm{~A}, 4$, and 6. Biochem. Biophys. Res. Commun. 247: 827-832.

Coschigano, P.W. and B. Magasanik. 1991. The URE2 gene product of Saccharomyces cerevisiae plays an important role in the cellular response to the nitrogen source and has homology to gluthathione S-transferases. Mol. Cell. Biol. 11: 822832 .

Courchesne, W.E. and B. Magasanik. 1988. Regulation of nitrogen assimilation in Saccharomyces cerevisiae: Roles of the URE2 and GLN3 genes. J. Bacteriol. 170: 708-713.

Cutler, N.S., J. Heitman, and M.E. Cardenas. 1999. TOR functions in a conserved signal transduction pathway that senses nutrient levels and growth factors and regulates protein synthesis and degradation. Mol. Cell. Endocrinol. 155: 135-142.

Di Como, C.J. and K.T. Arndt. 1996. Nutrients, via the Tor proteins, stimulate the association of Tap42 with type 2A phosphatases. Genes \& Dev. 10: 1904-1916.

Dilling, M.B., P. Dias, D.N. Shapiro, G.S. Germain, R.K. Johnson, and P.J. Houghton. 1994. Rapamycin selectively inhibits the growth of childhood rhabdomyosarcoma cells through inhibition of signaling via the type I insulin-like growth factor receptor. Cancer Res. 54: 903-907.

Fox, H.L., P.T. Pham, S.R. Kimball, L.S. Jefferson, and C.J. Lynch. 1998. Amino acid effects on translational repressor 4E-BP1 are mediated primarily by L-leucine in isolated adipocytes. Am. J. Physiol. 275: C1232-C1238.

Gimeno, C.J., P.O. Ljungdahl, C.A. Styles, and G.R. Fink. 1992. Unipolar cell divisions in the yeast $S$. cerevisiae lead to filamentous growth: Regulation by starvation and RAS. Cell 68: $1077-1090$.

Graves, L.M., K.E. Bornfeldt, G.M. Argast, E.G. Krebs, X. Kong, T.A. Lin, and J. John C. Lawrence. 1995. cAMP- and rapamycin-sensitive regulation of the association of eukaryotic initiation factor $4 \mathrm{E}$ and the translational regulator PHAS-I in aortic smooth muscle cells. Proc. Natl. Acad. Sci. 92: 7222 7226.

Hara, K., K. Yonezawa, Q.-P. Weng, M.T. Kozlowski, C. Belham, and J. Avruch. 1998. Amino acid sufficiency and mTOR regulate p70 S6 kinase and eIF-4E BP1 through a common effector mechanism. J. Biol. Chem. 273: 14484-14494.

Heitman, J., N.R. Movva, and M.N. Hall. 1991. Targets for cell cycle arrest by the immunosuppressant rapamycin in yeast. Science 253: 905-909.

Helliwell, S.B., P. Wagner, J. Kunz, M. Deuter-Reinhard, R. Henriquez, and M.N. Hall. 1994. TOR1 and TOR2 are structurally and functionally similar but not identical phosphatidyli- nositol kinase homologues in yeast. Mol. Biol. Cell 5: 105118.

Hosoi, H., M.B. Dilling, T. Shikata, L.N. Liu, L. Shu, R.A. Ashmun, G.S. Germain, R.T. Abraham, and P.J. Houghton. 1999. Rapamycin causes poorly reversible inhibition of mTOR and induces p53-independent apoptosis in human rhabdomyosarcoma cells. Cancer Res. 59: 886-894.

Iiboshi, Y., P.J. Papst, S.P. Hunger, and N. Terada. 1999a. LAsparaginase inhibits the rapamycin-targeted signaling pathway. Biochem. Biophys. Res. Commun. 260: 534-539.

Iiboshi, Y., P.J. Papst, H. Kawasome, J. Hosoi, R.T. Abraham, P.J. Houghton, and N. Terada. 1999b. Amino acid-dependent control of $\mathrm{p} 70^{\mathrm{s} 6 \mathrm{k}}$. Involvement of tRNA aminoacylation in the regulation. J. Biol. Chem. 274: 1092-1099.

Inui, S., H. Sanjo, K. Maeda, H. Yamamoto, E. Miyamoto, and N. Sakaguchi. 1998. Ig receptor binding protein 1 (alpha4) is associated with a rapamycin-sensitive signal transduction in lymphocytes through direct binding to the catalytic subunit of protein phosphatase 2A. Blood 92: 539-546.

Jiang, Y. and J.R. Broach. 1999. Tor proteins and protein phosphatase $2 \mathrm{~A}$ reciprocally regulate Tap42 in controlling cell growth in yeast. $E M B O$ J. 18: 2782-2792.

Kimball, S.R., L.M. Shantz, R.L. Horetsky, and L.S. Jefferson. 1999. Leucine regulates translation of specific mRNAs in L6 myoblasts through mTOR-mediated changes in availability of eIF4E and phosphorylation of ribosomal protein S6. J. Biol. Chem. 274: 11647-11652.

Kunz, J., R. Henriquez, U. Schneider, M. Deuter-Reinhard, N.R. Movva, and M.N. Hall. 1993. Target of rapamycin in yeast, TOR2, is an essential phosphatidylinositol kinase homolog required for $\mathrm{G}_{1}$ progression. Cell 73: 585-596.

Kuo, C.J., J. Chung, D.F. Fiorentino, W.M. Flanagan, J. Blenis, and G.R. Crabtree. 1992. Rapamycin selectively inhibits interleukin-2 activation of p70 S6 kinase. Nature 358: 70-73.

Lawrence, J.C., Jr. and R.T. Abraham. 1997. PHAS/4E-BPs as regulators of mRNA translation and cell proliferation. Trends Biochem. Sci. 22: 345-349.

Lin, T.A., X. Kong, A.R. Saltiel, P.J. Blackshear, and J.C. Lawrence. 1995. Control of PHAS-I by insulin in 3T3-L1 adipocytes. Synthesis, degradation, and phosphorylation by a rapamycin-sensitive and mitogen-activated protein kinaseindependent pathway. J. Biol. Chem. 270: 18531-18538.

Lorenz, M.C. and J. Heitman. 1997. Yeast pseudohyphal growth is regulated by GPA2, a $\mathrm{G}$ protein alpha homolog. EMBO $\mathrm{T}$. 16: $7008-7018$.

1998. The MEP2 ammonium permease regulates pseudohyphal differentiation in Saccharomyces cerevisiae. 17: 1236-1247.

Louro, I.D., P. McKie-Bell, H. Gosnell, B.C. Brindley, R.P. Bucy, and J.M. Ruppert. 1999. The zinc finger protein GLI induces cellular sensitivity to the mTOR inhibitor rapamycin. Cell Growth Differ. 10: 503-516.

Magasanik, B. 1992. Regulation of nitrogen utilization. In The molecular and cellular biology of the yeast Saccharomyces Gene expression. (ed. E.W. Jones, J.R. Pringle and J.R. Broach) Vol 2. pp. 283-317. Cold Spring Harbor Press, Cold Spring Harbor, NY.

Minehart, P.L. and B. Magasanik. 1991. Sequence and expression of $G L N 3$, a positive nitrogen regulatory gene of Saccharomyces cerevisiae encoding a protein with a putative zinc finger DNA-binding domain. Mol. Cell. Biol. 11: 6216-6228.

Mitchell, A.P. and B. Magasanik. 1983. Purification and properties of glutamine synthetase from Saccharomyces cerevisiae. J. Biol. Chem. 258: 119-124.

- 1984. Regulation of glutamine-repressible gene products by the GLN3 function in Saccharomyces cerevisiae. Mol. 
Cell. Biol. 4: 2758-2766.

Murata, K., J. Wu, and D.L. Brautigan. 1997. B cell receptorassociated protein alpha4 displays rapamycin-sensitive binding directly to the catalytic subunit of protein phosphatase 2A. Proc. Nat1. Acad. Sci. 94: 10624-10629.

Noda, T. and Y. Ohsumi. 1998. Tor, a phosphatidylinositol kinase homologue, controls autophagy in yeast. J. Biol. Chem. 273: 3963-3966.

Powers, T. and P. Walter. 1999. Regulation of ribosome biogenesis by the rapamycin-sensitive TOR-signaling pathway in Saccharomyces cerevisiae. Mol. Biol. Cell 10: 987-1000.

Price, D.J., J.R. Grove, V. Calvo, J. Avruch, and B.E. Bierer. 1992. Rapamycin-induced inhibition of the 70-kilodalton S6 protein kinase. Science 257: 973-977.

Sabatini, D.M., H. Erdjument-Bromage, M. Lui, P. Tempst, and S.H. Snyder. 1994. RAFT1: A mammalian protein that binds to FKBP12 in a rapamycin-dependent fashion and is homologous to yeast TORs. Cell 78: 35-43.

Sabers, C.J., M.M. Martin, G.J. Brunn, J.M. Williams, F.J. Dumont, G. Wiederrecht, and R.T. Abraham. 1995. Isolation of a protein target of the FKBP12-rapamycin complex in mammalian cells. J. Biol. Chem. 270: 815-822.

Schiestl, R.H., P. Manivasakam, R.A. Woods, and R.D. Gietz. 1993. Introducing DNA into yeast by transformation. Methods 5: 79-85.

Schmidt, A., T. Beck, A. Koller, J. Kunz, and M.N. Hall. 1998. The TOR nutrient signalling pathway phosphorylates NPR1 and inhibits turnover of the tryptophan permease. EMBO $T$. 17: 6924-6931.

Sherman, F. 1991. Getting started with yeast. Methods Enzymol. 194: 3-21.

Shi, Y., A. Frankel, L.G. Radvanyi, L.Z. Penn, R.G. Miller, and G.B. Mills. 1995. Rapamycin enhances apoptosis and increases sensitivity to cisplatin in vitro. Cancer Res. 55: 1982-1988.

Shigemitsu, K., Y. Tsujishita, K. Hara, M. Nanahoshi, J. Avruch, and K. Yonezawa. 1999. Regulation of translational effectors by amino acid and mammalian target of rapamycin signaling pathways. Possible involvement of autophagy in cultured hepatoma cells. J. Biol. Chem. 274: 1058-1065.

Stanbrough, M., D.W. Rowen, and B. Magasanik. 1995. Role of the GATA factors Gln3p and Nillp of Saccharomyces cerevisiae in the expression of nitrogen-regulated genes. Proc. Nat1. Acad. Sci. 92: 9450-9454.

Thomas, G. and M.N. Hall. 1997. TOR signalling and control of cell growth. Curr. Opin. Cell Biol. 9: 782-787.

von Manteuffel, S.R., A.-C. Gingras, X.-F. Ming, N. Sonenburg, and G. Thomas. 1996. 4E-BP1 phosphorylation is mediated by the FRAP-p $70^{\text {s6k }}$ pathway and is independent of mitogenactivated protein kinase. Proc. Natl. Acad. Sci. 93: 4076 4080.

Wach, A., A. Brachat, R. Pohlmann, and P. Philippsen. 1994. New heterologous modules for classical or PCR- based gene disruptions in Saccharomyces cerevisiae. Yeast 10: 1793-1808.

Weisman, R., M. Choder, and Y. Koltin. 1997. Rapamycin specifically interferes with the developmental response of fission yeast to starvation. J. Bacteriol. 179: 6325-6334.

Wickner R.B. 1994. [URE3] as an altered URE2 protein: Evidence for a prion analog in Saccharomyces cerevisiae. Science 264: 566-569.

Xu, G., G. Kwon, C.A. Marshall, T. Lin, J. J.C. Lawrence, and M.L. McDaniel. 1998. Branched-chain amino acids are essential in the regulation of PHAS-I and p70 S6 kinase by pancreatic $\beta$-cells. J. Biol. Chem. 273: 28178-28184.

$\mathrm{Xu}$, S., D.A. Falvey, and M.C. Brandriss. 1995. Roles of URE2 and GLN3 in the proline utilization pathway in Saccharo- myces cerevisiae. Mol. Cell. Biol. 15: 2321-2330.

Zaragoza, D., A. Ghavidel, J. Heitman, and M.C. Schultz. 1998. Rapamycin induces the $\mathrm{G}_{0}$ program of transcriptional repression in yeast by interfering with the TOR signaling pathway. Mol. Cell. Biol. 18: 4463-4470.

Zheng, X.F. and S.L. Schreiber. 1997. Target of rapamycin proteins and their kinase activities are required for meiosis. Proc. Natl. Acad. Sci. 94: 3070-3075.

Zheng, X.-F., D. Fiorentino, J. Chen, G.R. Crabtree, and S.L. Schreiber. 1995. TOR kinase domains are required for two distinct functions, only one of which is inhibited by rapamycin. Cell 82: 121-130. 


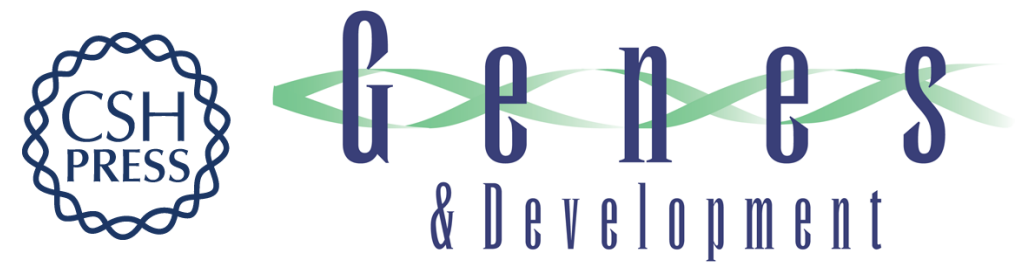

\section{The TOR signaling cascade regulates gene expression in response to nutrients}

Maria E. Cardenas, N. Shane Cutler, Michael C. Lorenz, et al.

Genes Dev. 1999, 13:

References This article cites 60 articles, 43 of which can be accessed free at:

http://genesdev.cshlp.org/content/13/24/3271.full.html\#ref-list-1

License

Email Alerting
Service

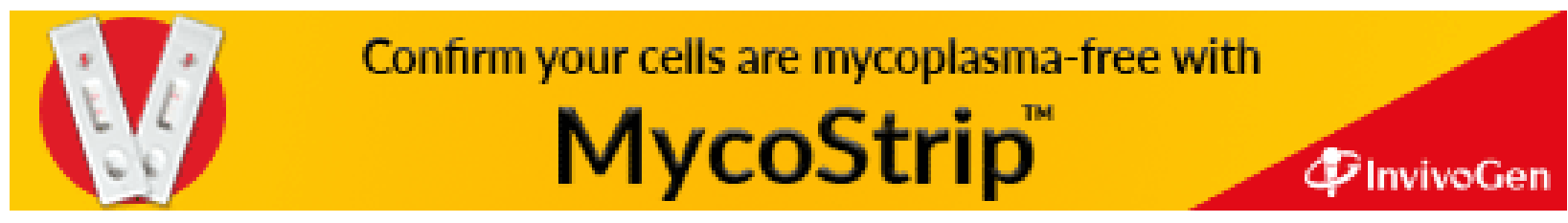

